\title{
Changes in The Use of After-Hour House-Call Medical Services For Fever or Common Cold Symptoms During The COVID-19 Pandemic in Tokyo, Japan: A Descriptive Study
}

Ryota INOKUCHI ( $\square$ intensivecareunits@gmail.com )

University of Tsukuba

Kojiro MORITA

University of Tsukuba

Masao IWAGAMI

University of Tsukuba

Taeko WATANABE

University of Tsukuba

Masatoshi ISHIKAWA

University of Tsukuba

Nanako TAMIYA

University of Tsukuba

\section{Research Article}

Keywords: Out-of-hours primary care, Quality, SARS, Triage, Severity

Posted Date: February 8th, 2021

DOl: https://doi.org/10.21203/rs.3.rs-152822/v1

License: (c) (i) This work is licensed under a Creative Commons Attribution 4.0 International License.

Read Full License 


\section{Abstract}

\section{Background}

The trend in the characteristics of patients using an after-hour house-call (AHHC) medical service changed the coronavirus disease of 2019 (COVID-19) pandemic, but there has been no report on this issue since the start of the COVID-19 pandemic. The aim of this study was to investigate patients' tendencies to seek an AHHC medical service for fever or common cold symptoms during the COVID-19 pandemic.

\section{Methods}

This cohort study compared the characteristics of patients with fever or symptoms of the common cold utilizing an AHHC medical service offered by a single large company between the control period (December 1, 2018 to April 30, 2019) and the COVID-19 pandemic exposure period (December 1, 2019 to April 30, 2020). It also assessed the proportion of these patients in relation to all patients calling for the service for any reason.

\section{Results}

During the control and COVID-19 pandemic exposure periods, 6,462 (median age: 8 [interquartile range $\{$ IQR\}: 3, 11], males: 48.2\%) and 10,003 (median age: 10 [IQR: 4, 33], males: 48.3\%) patients, respectively, called for the AHHC medical service. Of these, 5,335 (82.6\%) and 7,423 (74.2\%) patients had fever or common cold symptoms, respectively. The disease severity was differently distributed between the groups: the proportions of people with severe, moderate, and mild illness were $0.3 \%, 28.7 \%$, and $71.0 \%$ in the control period and $1.1 \%, 54.8 \%$, and $44.1 \%$ in the COVID-19 pandemic exposure period $(p<0.001)$, respectively. The AHHC medical service identified six individuals with COVID-19.

\section{Conclusions}

During the COVID-19 pandemic, the proportion of patients with fever or symptoms of the common cold was lower than that in the control period, but the illness severity was substantially higher.

\section{Background}

Since the identification of severe acute respiratory syndrome coronavirus 2 (SARS-CoV-2) at the end of 2019, the coronavirus disease (COVID-19) pandemic has resulted in a global health crisis [1]. Since January 2020, the number of COVID-19 cases has markedly increased in Japan, particularly in Tokyo [2, 3]. However, many health care providers at clinics and general hospitals have been reluctant to examine patients with fever or symptoms of the common cold, mainly due to difficulties in ensuring proper infection control measures, such as distancing of outpatients or the lack of personal protective equipment (PPE) for health care providers. It may also have been a possibility that patients did not want 
to visit clinics or hospitals for fear of becoming infected with SARS-CoV-2 in waiting and consultation rooms. These situations placed an additional burden on emergency departments (EDs).

A decade before the COVID-19 pandemic, ED overcrowding had become a significant worldwide public health problem [4]. Previous studies have reported that not all patients necessarily require an ambulance to reach an ED [5], and some reports have shown that $30 \%-80 \%$ of the patients can appropriately be treated in primary care settings $[6,7]$. To reduce unnecessary ambulance transport and thereby reduce ED overcrowding, many countries have recently launched after-hour house-call (AHHC) medical services [8].

In Tokyo, a private, non-governmental medical emergency service, which sends doctors directly to the patients' residences instead of sending an ambulance, has been operational since 2016. In Japan, generally, when a complaint arises out-of-hours and patients are unable to arrange for a house doctor, they usually call an ambulance directly, call an emergency telephone consultation service, call a home clinic or hospital, directly make a walk-in visit to an ED, or wait until a hospital opens. Emergency hospitals in Japan are divided into primary, secondary, and tertiary hospitals. When an ambulance is called, patients are transferred to a secondary or tertiary hospital, depending on the degree of severity. On the other hand, ambulatory patients can freely consult a primary hospital, a secondary hospital, or in some cases, a tertiary hospital, directly [9].

We hypothesized that the characteristics of patients using an AHHC medical service would change during the COVID-19 pandemic. To our knowledge, there has been no report on this issue since the start of the COVID-19 pandemic. Thus, we compared the characteristics of individuals making use of the AHHC medical service in Japan for complaints of fever or common cold symptoms between the COVID-19 pandemic period and the same period in the previous year.

\section{Methods}

\section{Data sources}

Since 2016 in Tokyo, Fast Doctor Ltd. (Shinjuku, Tokyo, Japan) has been running a private AHHC medical service which sends doctors directly to a patient's residence instead of sending an ambulance. The company operates seven days a week and outside of regular hospital visiting hours (19:00-6:00 on weekdays, 18:00-6:00 on Saturdays, and 24 hours a day on Sundays and holidays). The AHHC medical service has adopted a telephone triage approach. A well-used telephone triage in Japan is as follows; when a patient calls an emergency telephone consultation service, an operator classifies the patient into one of five categories (red, orange, yellow, green, or blue) based on acuity. The action for consultation is as follows: red: call an ambulance and deliver the patient to a secondary or tertiary emergency hospital; orange: provide the patient with information about a nearby secondary emergency hospital; yellow and green: provide the patient with information about nearby clinics or a primary hospital; and blue: provide the patient with advice for home observation [10]. 
The AHHC doctors also perform home visits for patients classified as orange and yellow, and following consultation, the doctor assesses the severity (mild, moderate, or severe) of the illness. The severity is classified as follows: mild: the patient can use over-the-counter drugs; moderate: the patient needs to visit a hospital or a clinic; and severe: an ambulance is needed. The number of visiting doctors per shift is four to twelve.

Before the start of the COVID-19 pandemic, operators of the AHHC medical service triaged patients with fever or common cold symptoms via telephone. After the start of the COVID-19 pandemic, operators assessed risk factors for COVID-19 in addition to performing the telephone triage; they also guided patients to call the consultation center in public health centers if COVID-19 was suspected, according to the Japanese government guidelines [11].

When COVID-19 was less suspected, doctors visited patients with fever at home if their triage level was orange or yellow. The visiting doctor used PPE while examining the patient and requested the SARS-CoV2 test using the polymerase chain reaction from a public health center if COVID-19 was suspected. All patients with fever were followed-up with a daily phone call until improvement of their symptoms. When patients tested positive for COVID-19, the AHHC medical service informed the public health centers and established contact with the patients. If the patient's condition deteriorated during the follow-up period, the visiting doctor assessed the severity and determined whether the patient should continue to be isolated at home, request admission to a hospital, or call an ambulance, regardless of their SARS-CoV- 2 test results (Figure 1).

In this study, the anonymized clinical records of all patients who had consulted the AHHC medical service were reviewed, and the following data of patients with fever as their chief complaint were extracted: sex, age, vital signs, triage level, and diagnosis. The current study was reviewed and approved by the Research Ethics Committee of the University of Tsukuba (approval number: 1527).

\section{Study period, studied population, and collected information}

We used the anonymized patients' data from Fast Doctor Ltd. from December 1, 2018 to April 30, 2020. During the study period, we first identified patients calling for AHHC services for any reason during the period; this number was used as the denominator. Among them, we identified patients with a fever, which is defined as body temperature $\geq 37.5^{\circ} \mathrm{C}$ according to the infectious disease control law in Japan, as well as those with symptoms of the common cold, the main population of interest in this study. To compare characteristics of patients with a fever or common cold symptoms between the COVID-19 pandemic exposure period (December 1, 2019 to April 30, 2020) and the control period (December 1, 2018 to April 30, 2019), the records of all patients who consulted Fast Doctor Ltd. during these periods were reviewed to obtain the following data: individuals' age and sex, the number of callers each month, diagnosis, and severity.

Statistical analysis 
First, we illustrated the number of patients with fever or symptoms of the common cold, and its proportion among all patients calling for the AHHC medical service (for any reason) during the 2-year study period. We compared the proportion between the COVID-19 pandemic exposure period (December 1 , 2019 to April 30, 2020) and the control period (December 1, 2018 to April 30, 2019) using a chi-square test. We also compared the characteristics (age, sex, number of patients per month, diagnosis, and triage category) of patients with fever or common cold symptoms using chi-square tests. Analyses were performed using JMP 14.3 statistical software (SAS Institute Inc., Cary, NC). The significance threshold was set at $p<0.05$.

\section{Results}

\section{Characteristics of patients with fever or symptoms of the common cold}

A total of 6,739 patients in the control period and 10,008 patients in the COVID-19 pandemic exposure period, respectively, consulted the AHHC medical service. We excluded 277 and 5 patients from the control and pandemic time periods, respectively, due to a lack of data in the age, sex, and triage categories, leaving a total of 6,462 and 10,003 patients seeking the AHHC medical service. Of these, 5,335 $(82.6 \%)$ and $7,423(74.2 \%)$ patients had fever or common cold symptoms in the control period and COVID-19 pandemic exposure period, respectively; their details are shown in Table 1.

The median age of patients in the control and exposure periods was 8 (interquartile range [IQR], 3-11) years and 10 (IQR, 4-33) years, respectively. Patients were predominantly < 15 years $(59.0 \%$ and $55.9 \%)$ and $15-64$ years $(39.6 \%$ and $41.6 \%)$, respectively, in these periods.

\section{Causes of fever}

Most diagnoses were upper respiratory tract infections, including influenza, streptococcal infections, tonsillitis, and sinusitis (Table 1). Among upper respiratory tract infections, the proportion of influenza infection was lower (42.1\% and $36.1 \%)$, while those of streptococcal infection (1.7\% and $2.7 \%)$ were higher than those during the control period $(p<0.001)$. During the exposure period, the AHHC medical service performed the SARS-CoV-2 test for 12 patients, six of whom had positive results (Table 1); an ambulance was dispatched for 1 patient, while the other five requested admission to the hospital.

\section{The proportion of patients with fever or common cold symptoms among AHHC medical service users}

Figure 2 shows the total number of patients calling the AHHC medical service and the proportion of patients with fever or common cold symptoms between December 1, 2018 and April 30, 2020. The number and proportion of patients with fever or common cold symptoms sharply dropped in April 2020.

After stratifying the patients into three age groups for both periods, the proportion of patients aged $\geq 65$ years with fever or symptoms of the common cold were higher in April during the exposure period than during the control period ( $0.3 \%$ and $0.5 \%$, respectively). 
The proportion of patients with fever or common cold symptoms assessed as severe increased $(0.2 \%$ and $0.9 \%$ ), and those assessed as moderate nearly doubled during the pandemic exposure period as compared to the control period ( $28.8 \%$ and $56.7 \%$, respectively; Table 1$)$. After stratifying the patients into three age groups, all age groups also showed severity that significantly increased in the exposure period compared to that in the control period $(p<0.001$, Table 2$)$.

\section{Discussion}

\section{General findings}

In this study, we show that among patients seeking an AHHC medical service in Japan, the proportion of patients with fever or common cold symptoms was slightly lower, but the severity of those patients was substantially higher in the COVID-19 exposure period than in the control period.

\section{Reduction in the proportion of patients with fever or common cold symptoms}

The proportion of patients with fever or symptoms of the common cold was slightly lower during the pandemic exposure period than that during the control period, and it decreased sharply in April, 2020. We had initially hypothesized that patients with fever or common cold symptoms may be reluctant to visit hospitals due to the risk of cross-infection and may have been concerned about which hospitals to approach, thus increasing the demand for the AHHC medical services after the start of the COVID-19 pandemic. However, the proportion of patients with fever or common cold symptoms seeking the AHHC medical service clearly decreased, particularly among patients $<65$ years of age in April, 2020.

The reason for this finding may be the initial declaration of a state of emergency in seven prefectures, including Tokyo, which occurred on April 7, 2020. Thereafter, many companies requested their employees to work from home, conduct meetings remotely, and restrict entry to the office, thereby achieving the government's goal of an $80 \%$ reduction in person-to-person contact [12]; this resulted in lower seasonal influenza activity in 2020 than in previous years [13]. In addition, this may have led to an increase in the opportunity of students and working people to consult a clinic or hospital during business hours. As for sick children, one parent could take the child to a pediatric clinic or hospital during business hours, while the other watched the other children at home.

Increase in the proportion of patients' severity

In contrast, the proportion of patients with more severe conditions was higher in the exposure period than in the control period. In Japan, at the beginning of the COVID-19 pandemic, patients with 1) a cold or a fever of $\geq 37.5^{\circ} \mathrm{C}$ lasting for $\geq 4$ days and 2 ) intense malaise or dyspnea, were recommended to consult a public health center as per the Japanese government guidelines. Thus, patients with fever or symptoms of the common cold may have refrained from visiting a hospital or a clinic, leading to a decrease in the 
number of patients in these medical settings; these patients may also have refrained from seeking an AHHC medical service, but would likely have resorted to one after becoming severe.

Patients with COVID-19 can progress to respiratory failure within hours [14-16]; in particular, those who are older in age and have chronic medical conditions have been associated with higher mortality [17-21]. In addition, EDs have been denying admission to some patients suspected of carrying SARS-CoV-2. For instance, in Tokyo, ED staff denied admission to an 80-year-old man suspected of having COVID-19 in 120 different hospitals [3]. Since early detection is crucial for older patients with fever, the AHHC medical service can contribute to early detection and reduce a patient's hesitation to call an ambulance.

\section{Reducing the risk of cross-infections}

The AHHC medical team identified 6 individuals with COVID-19 by SARS-CoV-2 testing. Direct person-toperson contact via respiratory droplets or indirect contact by touching the eyes, nose, or mouth after touching infected surfaces is the main transmission pathway of SARS-CoV-2 [22]. The Centers for Disease Control have recommended that outpatients with suspected COVID-19, including those awaiting test results, should stay at home and isolate themselves from other people [23]; however, in Japan, people need to visit a clinic or a hospital for SARS-CoV-2 testing. Thus, outpatients in the ED or those on the way to the ED are likely to have contributed to transmission. In the AHHC medical service, doctors wearing PPE visit patients at home, likely reducing the risk of cross-infections in the community and hospital.

Reduction of the burden on emergency departments for patients with fever or symptoms of the common cold

The AHHC service provided more than 7,000 medical services since the start of the COVID-19 pandemic. On April 20, 2020, 9 prefectures, including Tokyo, reported that their hospitals were already at $80 \%$ capacity, and a public broadcaster in Japan reported that a patient with COVID-19 symptoms had been turned away by 80 hospitals in Tokyo [3]. Outpatient management is appropriate for most patients with COVID-19; in approximately $80 \%$ of the patients, the illness is mild and does not warrant medical intervention or hospitalization [24]. Thus, the AHHC medical service might have been a buffer for consultations for patients with suspected COVID-19.

Reducing the burden on public health centers, clinics, and patients

In Japan, at the beginning of the COVID-19 pandemic, the public health center advised patients to visit a medical institution designated for SARS-CoV-2 infectious diseases. After the initial period, the public health center and medical institution gradually became busier; thus, the administration asked general clinics and hospitals to receive patients with fever and mild cold symptoms. However, many clinics and hospitals were reluctant to examine patients with fever because of difficulties in achieving proper infection control measures, such as separation of outpatients and inpatients with fever. The AHHC medical service may reduce the burden on public health centers, clinics, and patients due to the AHHC operation, home visits, and direct consultations with the public health center on behalf of the patient. 


\section{Limitations}

There were some limitations to the current study. First, we reported only a single AHHC medical service. However, this AHHC service provides more than 18,000 night visits annually and is the largest out-ofhours emergency service in Japan. Second, we only compared two periods. After April 10, 2020, the Japanese government lifted restrictions on first-time patients online or via telephone; thus, patients no longer needed to visit a clinic or a hospital. In addition, telemedicine has been covered by Japan's National Health Insurance program. The medical situation has changed markedly; thus, we only compared the patients from December to April for each period. Finally, the AHHC service has a low usage rate among the elderly who may not be familiar with its use as the AHHC was started in 2016.

\section{Conclusion}

Among older patients seeking an AHHC medical service, we demonstrated a significant decrease in the proportion of patients with fever or common cold symptoms, but a substantial increase in the severity of disease during the period of social distancing and tighter regulations to prevent the spread of COVID-19. This information may be helpful in driving government policy and social behavior in the upcoming months.

\section{Abbreviations}

after-hour house-call (AHHC), coronavirus disease (COVID), emergency department (ED), interquartile range (IQR), personal protective equipment (PPE), severe acute respiratory syndrome coronavirus 2 (SARS-CoV-2)

\section{Declarations}

\section{Funding}

This work was supported by grants from Fast Doctor Ltd.

\section{Consent for publication}

Not applicable [individual-level data not included].

\section{Acknowledgements}

Not applicable.

\section{Contributions}

R.I., K.M., T.W., Ishikawa, M., and N.T. conceived the study. R.I., K.M., T.W., and N.T. collected the data. R.I. performed statistical analyses and wrote the first draft of this study. Iwagami, M. and N.T. critically 
reviewed the manuscript. All authors contributed to the design, interpretation of results, and critical revision of the article for intellectually important content.

\section{Ethics declarations}

Ethics approval and consent to participate

The Research Ethics Committee of University of Tsukuba approved this study (approval number: 1527) and waived informed consent. All methods were performed in accordance with the relevant guidelines and regulations.

\section{Availability of data and material}

The datasets used and/or analyzed during the current study available from the corresponding author on reasonable request.

\section{Competing interests}

1) Rl's joint appointment as an associate professor and 2) KM's and TW's appointment as an assistant professor at the University of Tsukuba were sponsored by Fast DOCTOR Ltd. from October 2019 to the present. Fast DOCTOR Ltd. had no role in conducting this study. Iwagami, M., T.W., Ishikawa, M., and N.T. have no conflict of interest.

\section{References}

1. Zhu N, Zhang D, Wang W, Li X, Yang B, Song J, Zhao X, Huang B, Shi W, Lu R et al: A Novel Coronavirus from Patients with Pneumonia in China, 2019. N Engl J Med 2020;382(8):727-733.

2. Looi MK: Covid-19: Japan declares state of emergency as Tokyo cases soar. BMJ 2020;369:m1447.

3. Hayasaki E: Covid-19: how Japan squandered its early jump on the pandemic. BMJ 2020;369:m1625.

4. Hoot NR, Aronsky D: Systematic review of emergency department crowding: causes, effects, and solutions. Ann Emerg Med 2008;52(2):126-136.

5. Booker MJ, Shaw AR, Purdy S: Why do patients with 'primary care sensitive' problems access ambulance services? A systematic mapping review of the literature. BMJ Open 2015;5(5):e007726.

6. Gratton MC, Ellison SR, Hunt J, Ma OJ: Prospective determination of medical necessity for ambulance transport by paramedics. Prehosp Emerg Care 2003;7(4):466-469.

7. Patton GG, Thakore S: Reducing inappropriate emergency department attendances-a review of ambulance service attendances at a regional teaching hospital in Scotland. Emerg Med J 2013;30(6):459-461.

8. http://www.health.gov.au/internet/main/publishing.nsf/Content/primary-ahphc-review (Accessed on November 01, 2020). 
9. Inokuchi R, Sato H, Nakajima S, Shinohara K, Nakamura K, Gunshin M, Hiruma T, Ishii T, Matsubara T, Kitsuta $Y$ et al: Development of information systems and clinical decision support systems for emergency departments: a long road ahead for Japan. Emerg Med J 2013.

10. Sakurai A, Morimura N, Takeda M, Miura K, Kiyotake N, Ishihara T, Aruga T: A retrospective quality assessment of the 7119 call triage system in Tokyo - telephone triage for non-ambulance cases. J Telemed Telecare 2014;20(5):233-238.

11. https://www.mhlw.go.jp/content/10900000/000620733.pdf (Accessed on Nonember 01, 2020).

12. https://jp.usembassy.gov/health-alert-us-embassy-tokyo-april29-2020/ (Accessed on November 01, 2020).

13. Sakamoto H, Ishikane M, Ueda P: Seasonal Influenza Activity During the SARS-CoV-2 Outbreak in Japan. JAMA 2020;323(19):1969-1971.

14. Chan JF, Yuan S, Kok KH, To KK, Chu H, Yang J, Xing F, Liu J, Yip CC, Poon RW et al: A familial cluster of pneumonia associated with the 2019 novel coronavirus indicating person-to-person transmission: a study of a family cluster. Lancet 2020;395(10223):514-523.

15. Phan LT, Nguyen TV, Luong QC, Nguyen HT, Le HQ, Nguyen TT, Cao TM, Pham QD: Importation and Human-to-Human Transmission of a Novel Coronavirus in Vietnam. N Engl J Med 2020;382(9):872874.

16. Burki TK: Coronavirus in China. Lancet Respir Med 2020;8(3):238.

17. Lighter J, Phillips M, Hochman S, Sterling S, Johnson D, Francois F, Stachel A: Obesity in Patients Younger Than 60 Years Is a Risk Factor for COVID-19 Hospital Admission. Clin Infect Dis 2020;71(15):896-897.

18. Richardson S, Hirsch JS, Narasimhan M, Crawford JM, McGinn T, Davidson KW, Barnaby DP, Becker LB, Chelico JD, Cohen SL et al: Presenting Characteristics, Comorbidities, and Outcomes Among 5700 Patients Hospitalized With COVID-19 in the New York City Area. JAMA 2020;323(20):20522059.

19. Docherty AB, Harrison EM, Green CA, Hardwick HE, Pius R, Norman L, Holden KA, Read JM, Dondelinger F, Carson $G$ et al: Features of 20133 UK patients in hospital with covid-19 using the ISARIC WHO Clinical Characterisation Protocol: prospective observational cohort study. BMJ 2020;369:m1985.

20. Zhou F, Yu T, Du R, Fan G, Liu Y, Liu Z, Xiang J, Wang Y, Song B, Gu X et al: Clinical course and risk factors for mortality of adult inpatients with COVID-19 in Wuhan, China: a retrospective cohort study. Lancet 2020;395(10229):1054-1062.

21. Onder G, Palmieri L, Vanacore N, Giuliano M, Brusaferro S, Group INIoHC-M: Nonrespiratory Complications and Obesity in Patients Dying with COVID-19 in Italy. Obesity (Silver Spring) 2020 [In press].

22. https://www.who.int/docs/default-source/coronaviruse/situation-reports/20200122-sitrep-2-2019ncov.pdf (Accessed on November 01, 2020). 
23. https://www.cdc.gov/coronavirus/2019-ncov/prevent-getting-sick/how-covid-spreads.html (Accessed on November 01, 2020).

24. https://www.who.int/publications-detail/report-of-the-who-china-joint-mission-on-coronavirusdisease-2019-(covid-19) (Accessed on November 01, 2020).

\section{Tables}

Table 1. Characteristics of patients with fever for each period. 


\begin{tabular}{|c|c|c|c|}
\hline & $\begin{array}{l}\text { The control period } \\
(\mathrm{N}=5,335)\end{array}$ & $\begin{array}{l}\text { The exposure period } \\
(\mathrm{N}=7,423)\end{array}$ & $P$ value \\
\hline \multicolumn{4}{|l|}{ Age } \\
\hline Median [IQR] age (years) & $8[3-11]$ & $10[4-33]$ & $<0.001$ \\
\hline Distribution -no./total no. (\%) & & & $<0.001$ \\
\hline $0-14$ year $(\%)$ & $3,147(59.0)$ & $4,152(55.9)$ & \\
\hline 15-64 year (\%) & 2,112 (39.6) & $3,089(41.6)$ & \\
\hline $65-$ year $(\%)$ & $76(1.4)$ & $182(2.5)$ & \\
\hline Female sex -no./total no. (\%) & $2,765(51.8)$ & $3,839(51.7)$ & 0.90 \\
\hline \multicolumn{4}{|l|}{ Month -no./total no. (\%) } \\
\hline December & $523(9.8)$ & $1,683(22.7)$ & \\
\hline January & $1,704(31.9)$ & $2,052(27.6)$ & \\
\hline February & $1,243(23.3)$ & $2,062(27.8)$ & \\
\hline March & $900(16.9)$ & $1,057(14.2)$ & \\
\hline April & $968(18.1)$ & $570(7.7)$ & \\
\hline \multicolumn{4}{|l|}{ Diagnosis -no. (\%) } \\
\hline Upper respiratory tract infections & $\mathrm{N}=4555$ & $N=5875$ & \\
\hline - Influenza & $1,916(42.1)$ & $2,119(36.1)$ & $<0.001$ \\
\hline - Streptococcal Infections & $78(1.7)$ & $161(2.7)$ & $<0.001$ \\
\hline - Tonsillitis & $191(4.1)$ & $254(3.4)$ & 0.63 \\
\hline - Sinusitis & $15(0.3)$ & $34(0.6)$ & 0.11 \\
\hline - COVID-19 & 0 & $6(0.1)$ & 0.038 \\
\hline Pneumonia & $38(0.7)$ & $61(0.8)$ & 0.49 \\
\hline Asthma & $48(0.9)$ & $40(0.5)$ & 0.021 \\
\hline Otitis media & $72(1.3)$ & $106(1.4)$ & 0.71 \\
\hline Urinary tract infection & $24(0.4)$ & $67(0.9)$ & $<0.001$ \\
\hline Gastroenteritis & $773(13.9)$ & $1,064(14.3)$ & 0.22 \\
\hline s/o Abdominal disease & $35(0.6)$ & $82(1.1)$ & $<0.001$ \\
\hline Other & $138(2.5)$ & $427(5.7)$ & $<0.001$ \\
\hline \multicolumn{3}{|c|}{ Telephone triage category -no./total no. (\%) } & $<0.001$ \\
\hline
\end{tabular}




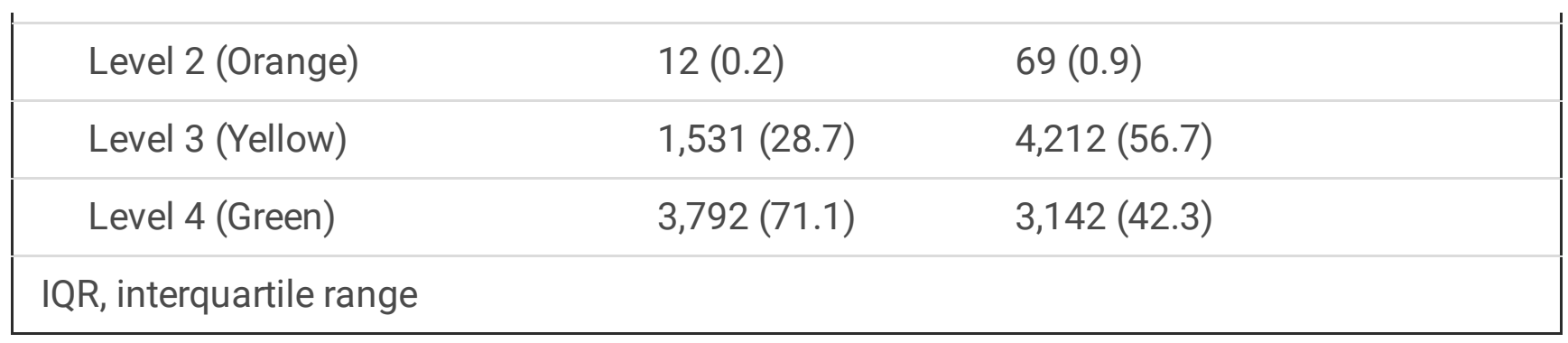

Table 2. Comparison of the severity level of each period according to age.

\begin{tabular}{|c|c|c|c|c|}
\hline & $\begin{array}{l}\text { The control period } \\
(\mathrm{N}=5,335)\end{array}$ & $\begin{array}{l}\text { The exposure period } \\
(\mathrm{N}=7,423)\end{array}$ & chi-squared value & $p$ value \\
\hline \multicolumn{5}{|l|}{ Age $<15$} \\
\hline Severity & & & 597.8 & $<0.001$ \\
\hline Level 1 (severe) & $5(0.2)$ & $13(0.3)$ & & \\
\hline Level 2 (moderate) & $855(27.1)$ & $2297(55.3)$ & & \\
\hline Level 3 (mild) & $2287(72.7)$ & $1842(44.4)$ & & \\
\hline \multicolumn{5}{|l|}{ Age $15-64$} \\
\hline Severity & & & 428.0 & $<0.001$ \\
\hline Level 1 (severe) & $5(0.2)$ & $30(1.0)$ & & \\
\hline Level 2 (moderate) & $652(30.9)$ & $1821(59.0)$ & & \\
\hline Level 3 (mild) & $1495(68.9)$ & $1238(40.1)$ & & \\
\hline \multicolumn{5}{|l|}{ Age $65<$} \\
\hline Severity & & & 25.2 & $<0.001$ \\
\hline Level 1 (severe) & $2(2.7)$ & $26(14.3)$ & & \\
\hline Level 2 (moderate) & $24(31.6)$ & $94(51.7)$ & & \\
\hline Level 3 (mild) & $50(65.8)$ & $62(34.1)$ & & \\
\hline
\end{tabular}

\section{Figures}


Private

medical emergency service

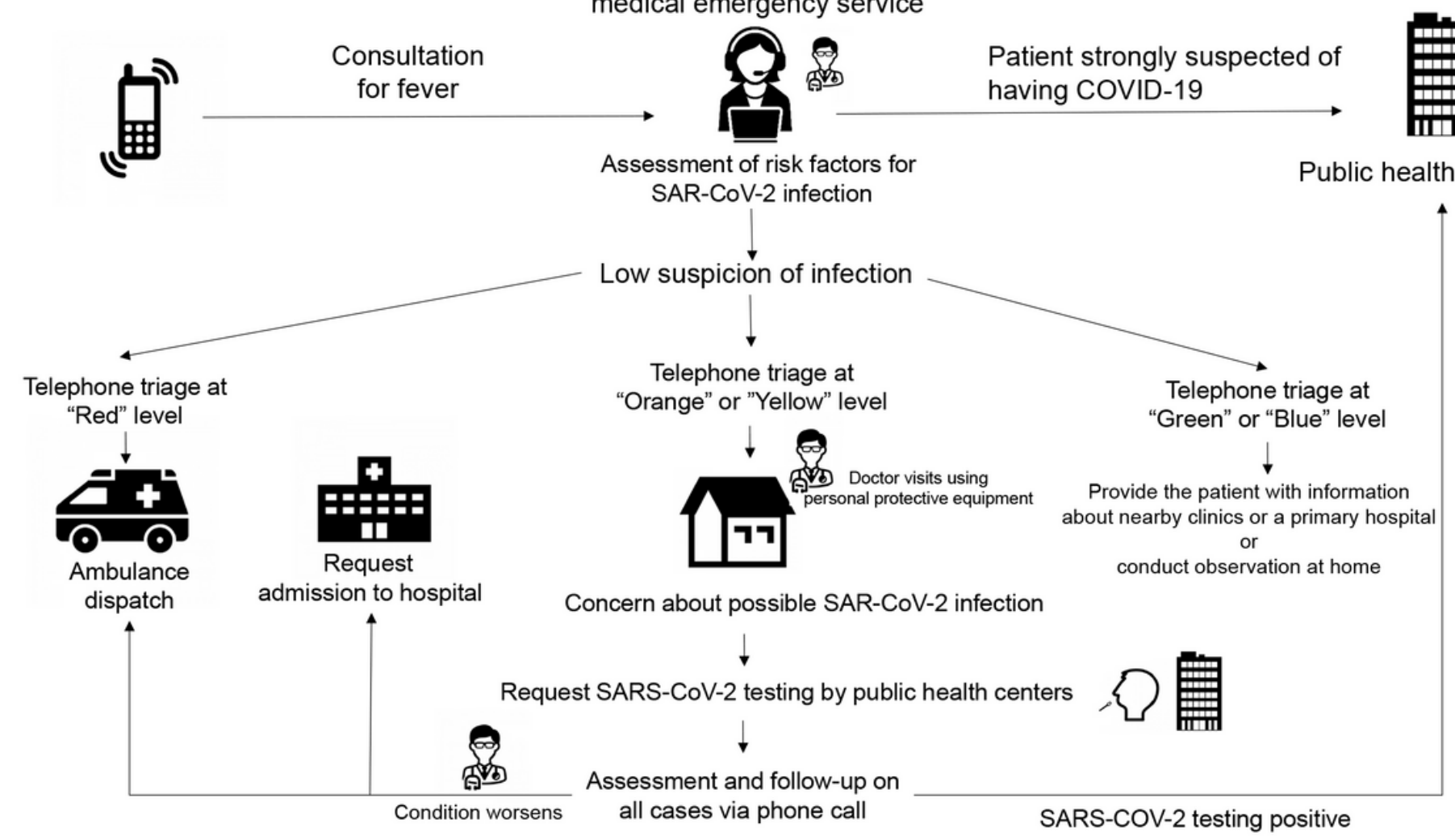

Figure 1

Flow of patients who consulted the after-hour house-call medical service. The operators of the private medical emergency service assess risk factors for SARS-CoV-2 infection. If infection is suspected, the operators consult a doctor and guide the patients to call public health centers. Then, based on the telephone triage (red, orange, yellow, green, and blue), the operators determine whether the patient is to remain at home or (blue), they opt to provide the patient with information about nearby clinics or a primary hospital (green), a doctor's visit to the patient's residence (orange and yellow), or an ambulance (red). 


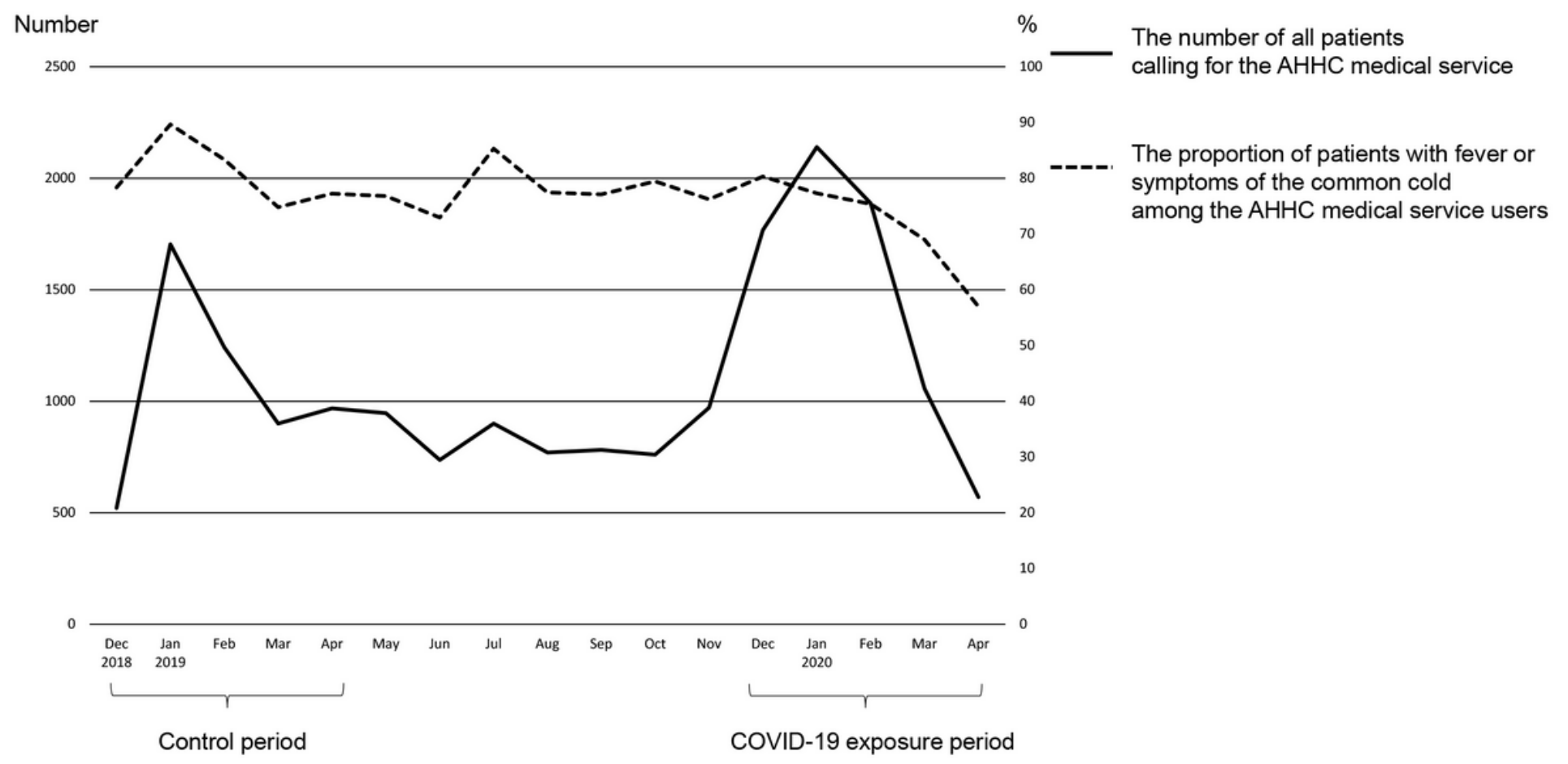

\section{Figure 2}

Time-related changes in the number and proportion of patients between December 1, 2018 and April 30, 2020. The period from December 1, 2018 to April 30, 2019 was defined as the control period. The period from December 1, 2019 to April 30, 2020 was defined as the COVID-19 pandemic exposure period. AHHC, after-hour house-call. 